\title{
Metastatic Cholangiocarcinoma
}

National Cancer Institute

\section{Source}

National Cancer Institute. Metastatic Cholangiocarcinoma. NCI Thesaurus. Code C157623.

A carcinoma that arises from the intrahepatic biliary tree and has metastasized to other anatomic sites. 